\title{
Cataract-aberrant oral frenula-growth delay syndrome
}

INSERM

\section{Source}

INSERM. (1999). Orphanet: an online rare disease and orphan drug data base. Cataractaberrant oral frenula-growth delay syndrome. ORPHA:1373

Cataract-aberrant oral frenula-growth delay syndrome is characterized by cataracts and short stature associated with variable anomalies, including aberrant oral frenula, a characteristic facial appearance (posteriorly angulated ears, upslanting palpebral fissures, small nose, ptosis and epicanthal folds) cavernous hemangiomas and hernias. It has been described in a mother and her two children. It is transmitted as an autosomal dominant trait. 